\title{
A study comparing vaginal misoprostol alone with vaginal misoprostol in combination with Foley catheter for cervical ripening and labour induction
}

\author{
Binti R. Bhatiyani*, Manisha R. Gandhewar, Swati Kapsikar, Pradip Gaikwad
}

Department of Obstetrics and Gynaecology, ESIPGIMSR, Andheri, Mumbai, Maharashtra, India

Received: 23 November 2016

Accepted: 20 December 2016

\section{*Correspondence:}

Dr. Binti R. Bhatiyani,

E-mail: bintirlb@yahoo.co.in

Copyright: (c) the author(s), publisher and licensee Medip Academy. This is an open-access article distributed under the terms of the Creative Commons Attribution Non-Commercial License, which permits unrestricted non-commercial use, distribution, and reproduction in any medium, provided the original work is properly cited.

\section{ABSTRACT}

Background: Induction of labor is a commonly practised intervention in modern obstetrics. The objective of this study was to compare the efficacy of vaginal misoprostol alone with vaginal misoprostol in combination with Foley catheter for labour induction. It aims to assess the induction delivery interval, the outcome of labour, the incidence of instrumental delivery and Cesarean section. The neonatal outcomes and maternal complications would also be assessed.

Methods: 105 women with singleton viable pregnancies of 28 weeks or more gestation with cephalic presentation, intact membranes and an unfavorable cervix (Bishops score less than 6) were randomly assigned to induction of labor using vaginal misoprostol or Foley catheter in combination with vaginal misoprostol. Women in the misoprostol only group received 25 micrograms of misoprostol per vagina every 4 hours for a maximum of six doses. Whereas women in the combination group received vaginal misoprostol and in addition Foley catheter was introduced through the cervix for 12 hours. Interruption of the trial was done in case of failure to enter the active phase of labour after 24 hours of induction, fetal distress, hyperstimulation, hypersensitivity to drugs.

Results: The induction to delivery time was shorter in misoprostol group as compared to the Foley with misoprostol group by 3 hours. There was no significant change in Bishops score after induction with Foley in combination with misoprostol as compared to misoprostol alone. There was no increase in the maternal and fetal complications in the misoprostol group as compared to Foley with misoprostol.

Conclusions: Misoprostol alone was more efficacious for ripening and inducing agent as compared to Foley in combination with misoprostol.

Keywords: Cervical ripening, Foley catheter, Labour induction, Misoprostol

\section{INTRODUCTION}

A study comparing vaginal misoprostol alone with vaginal misoprostol in combination with Foley catheter for cervical ripening and labour induction Induction of labour can be defined as the artificial induction of labour, before its spontaneous onset, for the purpose of delivery of the fetoplacental unit. ${ }^{1}$

Labour induction is one of the most common procedures performed in Obstetrics, reaching $10-20 \%$ of deliveries worldwide, but its success depends largely on the condition of the cervix. ${ }^{2}$

The goal of induction of labor is to achieve vaginal delivery in a safe and timely manner. Thus although the best agent and method for induction of labor remains uncertain, it is biologically plausible that a combination of a mechanical device (Foley bulb) and chemical agent (synthetic prostaglandin) may have an additive effect, resulting in a greater degree of cervical ripening and shorter induction to delivery time. The addition of a 
synthetic prostaglandin to the Foley bulb may also overcome the scenario of frequent dilatation with the Foley bulb without significant effacement.

\section{METHODS}

This was a randomized clinical trial comparing the efficacy of vaginal misoprostol alone with vaginal misoprostol in combination with Foley catheter.

The study was approved by the hospital ethics committee. All women with a singleton, viable gestation 28 weeks or greater, cephalic presentation, intact membranes and an unfavourable cervix (Bishops score 6 or less) presenting for labour induction from January 2013 to November 2014 were evaluated for participation.

Women were excluded if any of the following criteria were encountered fetal malpresentation, multifetal gestation, spontaneous labour, more than 5 uterine contractions in 10 minutes, contraindication to prostaglandins, fetal demise, anomalous fetus, fetal heart tracings showing decelerations, tachycardia or bradycardia or previous Cesarean delivery or other uterine surgery e.g. myomectomy, cornual wedge resection. Eligible patients were approached for consent to participate in the study if inclusion criteria had been met.

Women in the misoprostol only group received 25 micrograms of misoprostol per vagina every 4 hours for a maximum of six doses. Once the cervix became favourable (Bishops score more than 6) or the patient was in active labour, misoprostol was discontinued. Further management of labour was with expectant management, amniotomy or intravenous oxytocin as per unit protocol. If indicated oxytocin was started as per standard protocol 4 hours from the last misoprostol dose. Oxytocin was administered per standard protocol starting at 2 milliunits/min increasing by 2 milliunits/min every half an hour. Interruption of the trial was done in case of failure to enter the active phase of labour after 24 hours of induction, fetal distress, hyperstimulation, hypersensitivity to drugs.

Women in the combination group received vaginal misoprostol as per standard protocol at 25 micrograms every 4 hours for a maximum of six doses. In addition, a Foley catheter was inserted digitally or by direct visual examination with the aid of a sterile speculum. The Foley was inserted through the internal os, filled with $40 \mathrm{ml}$ of normal saline, and then pulled snugly against the internal os. The catheter was taped to patient's inner thigh under gentle traction. The Foley was removed after 12 hours if it was not spontaneously expelled. When the Foley bulb was expelled, further management of labour was either expectant, amniotomy or IV oxytocin. Other aspects of labour management was similar in both groups including continuous electronic fetal monitoring. The primary outcome measure was induction to delivery interval.
Secondary outcome measures were mode of delivery, tachysystole (defined as greater than five uterine contractions in 5 minutes), $\mathrm{PPH}$ defined as estimated blood loss greater than $500 \mathrm{ml}$ for vaginal delivery or greater than $1000 \mathrm{ml}$ for Cesarean delivery, neonatal Apgar scores and neonatal intensive care admissions.

\section{RESULTS}

A total of 105 women were enrolled for the study from January 2013 to November 2014. Of these 51 women were assigned to vaginal misoprostol and 54 with Foley with misoprostol. The two groups were comparable with regards to baseline characteristics including the indications for induction of labor. The distribution of patients according to parity was also statistically not significant, Tables 1-3.

Table 1: Age distribution of patients in the study.

\begin{tabular}{|l|l|l|}
\hline Age in years & \multicolumn{2}{|l|}{ Inducing agent } \\
& Misoprostol & $\begin{array}{l}\text { Foley with } \\
\text { misoprostol }\end{array}$ \\
\hline Up to 25 years & $30(58.8 \%)$ & $34(63.0 \%)$ \\
\hline 26 to 30 years & $16(31.4 \%)$ & $10(18.5 \%)$ \\
\hline 31 to 35 years & $5(9.8 \%)$ & $10(18.5 \%)$ \\
\hline Total & $\mathbf{5 1}$ & $\mathbf{5 4}$ \\
\hline Mean & $\mathbf{2 5 . 4 9}$ & $\mathbf{2 5 . 8 0}$ \\
\hline
\end{tabular}

Table 2: Distribution of patients according to parity.

\begin{tabular}{|l|l|l|}
\hline Parity & \multicolumn{2}{|c|}{ Inducing agent } \\
\hline Nulliparous & $20(39.2 \%)$ & $27(50 \%)$ \\
\hline Multiparous & $31(60.8 \%)$ & $27(50 \%)$ \\
\hline
\end{tabular}

Table 3: Distribution of patients according to indications for induction of labour.

\begin{tabular}{|l|l|l|}
\hline Inducing agent & Misoprostol & $\begin{array}{l}\text { Foley plus } \\
\text { misoprostol }\end{array}$ \\
\hline Postdatism & $25(49 \%)$ & $22(40.7 \%)$ \\
\hline PIH & $14(27.5 \%)$ & $24(44.4 \%)$ \\
\hline IUGR & $5(9.8 \%)$ & $6(11.1 \%)$ \\
\hline Oligohydramnios & $7(13.7 \%)$ & $2(3.7 \%)$ \\
\hline
\end{tabular}

Table 4: Mean Bishops scores after induction.

\begin{tabular}{|l|l|l|}
\hline Hours & Bishops score & \\
\hline & Misoprostol & Foley with misoprostol \\
\hline 0 & 3 & 1.63 \\
\hline 4 & 7 & 5 \\
\hline 8 & 8 & 7 \\
\hline 12 & 10 & 8 \\
\hline
\end{tabular}

Most of the patients were term. The most common indication for induction was postdatism. The mean Bishops score was similar in the two groups. In the 
course of the study, it was noted that there was no significant difference in the improvement in Bishops score between the two groups 12 hours after induction. Table 4.

Table 5: Mean Induction delivery interval.

\begin{tabular}{|l|l|l|}
\hline Misoprostol & Foley with misoprostol & p value \\
\hline 8.15 hours & 10.75 hours & 0.005 \\
\hline
\end{tabular}

It was noted that the mean induction delivery interval was shorter in misoprostol group by a mean of 3 hours when compared with those induced with Foley bulb in

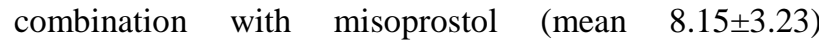
compared with (mean 10.75 \pm 3.82 hours), the difference being statistically significant $(\mathrm{p}=0.005)$ Table 5 .

In present study, there was a higher rate of vaginal delivery in misoprostol group $(64.7 \%)$ as compared to the combination group (50\%). However, this was not statistically significant. There were no differences in oxytocin augmentation in the two groups. Labor characteristics and complications are shown in Tables 6 and 7. Although the various indications for Cesarean were statistically not significant, higher rate of Cesarean section was done for fetal distress in the combination group tha in the misoprostol only group (53.\%) vs (44.\%)

Table 6: Distribution of patients according to the mode of delivery.

\begin{tabular}{|l|l|l|}
\hline Mode of Delivery & \multicolumn{2}{c|}{ Inducing Agent } \\
& Misoprostol & $\begin{array}{l}\text { Foley with } \\
\text { misoprostol }\end{array}$ \\
\hline Spontaneous vaginal & $33(64.7 \%)$ & $28(50.0 \%)$ \\
\hline Forceps & nil & nil \\
\hline Ventouse & nil & nil \\
\hline Caesarean Section & $18(35.3 \%)$ & $26(46.3 \%)$ \\
\hline
\end{tabular}

Table 7: Complications and side effects.

\begin{tabular}{|l|l|l|}
\hline $\begin{array}{l}\text { Complications and } \\
\text { side effects }\end{array}$ & Misoprostol & $\begin{array}{l}\text { Foley with } \\
\text { misoprostol }\end{array}$ \\
\hline Hyper stimulation & nil & nil \\
\hline Nausea and vomiting & $3(5.9 \%)$ & $4(7.4 \%)$ \\
\hline Fever & $5(9.8)$ & $6(11.1)$ \\
\hline Fetal Distress & $8(44.44 \%)$ & $14(53.84 \%)$ \\
\hline Rupture uterus & None & None \\
\hline Chorioamnionitis & none & none \\
\hline
\end{tabular}

There was no difference in the incidence of tachysystole, use of terbutaline, or meconium passage in the two groups. The risks of chorioamnionitis, endometritis, and PPH were also not significantly different in the two groups. The neonatal outcomes are shown in Table 8. There were no differences in birth weight, Apgar scores in the two groups. Though there was a higher rate of
NICU admission in misoprostol as compared to Foley plus misoprostol group, this was statistically not significant $(\mathrm{p}=1.38)$.

Table 8: Neonatal outcome.

\begin{tabular}{|c|c|c|}
\hline Neonatal Outcomes & \multicolumn{2}{|c|}{ Inducing Agent } \\
\hline & Misoprostol & $\begin{array}{l}\text { Foley with } \\
\text { misoprostol }\end{array}$ \\
\hline APGAR at $1 \mathrm{~min}$ & 8.24 & 8.52 \\
\hline APGAR at $5 \mathrm{~min}$ & 8.84 & 9.04 \\
\hline NICU admission & 11 & 7 \\
\hline Stillbirths & Nil & Nil \\
\hline Neonatal deaths & Nil & Nil \\
\hline Mean birth wt in kgs & 2.72 & 2.68 \\
\hline
\end{tabular}

\section{DISCUSSION}

We found that the induction to delivery interval was shorter by 3 hours in the misoprostol only group. No differences were observed in labour complications or adverse neonatal and maternal outcomes. In the randomized study conducted by Carbone et al, where 123 women were enrolled, the use of Foley bulb and vaginal misoprostol shortened induction to delivery time by an average of 3 hours compared with vaginal misoprostol alone. ${ }^{3}$ Whereas in another randomized trial by Kashanian et al, combination of the two methods did not increase their effectiveness and there seemed to be no synergistic effects. ${ }^{4}$ Also the induction delivery interval was shorter in the vaginal misoprostol alone than in the combination of Foley bulb and vaginal misoprostol. Chung et al reported no difference in induction to delivery time between the three arms comparing vaginal misoprostol alone, misoprostol in combination with Foley bulb or with Foley bulb alone. ${ }^{5}$ Contrary to present study their study, reported a statistically significant increase in tachysystole, terbutaline use and chorioamnionitis with misoprostol alone when compared with the combination group.

\section{CONCLUSION}

Induction to delivery time was shorter in misoprostol group as compared to Foley in combination with misoprostol by three hours. There were no increased maternal and fetal complications of misoprostol as compared to Foley with misoprostol. There were no differences in oxytocin augmentation in the two groups. There was no significant difference in the improvement in Bishops score between the two groups 12 hours after induction .There was no statistically significant difference in the mode of delivery between the two groups.

\section{ACKNOWLEDGEMENTS}

Authors would like to thank the Dean of the institute Dr Meenakshi Mathur for her guidance and support. 
Funding: No funding sources

Conflict of interest: None declared

Ethical approval: The study was approved by the Institutional Ethics Committee

\section{REFERENCES}

1. Joan Crane St, Johns NF, Line L, Gregory JR. Induction of labour at term. J Obstet Gynaecol Can. 2001;23:717-28

2. Guerra GV, Cecatti JG, Souza JP, Faundes A, Morais SS, Gulmezoglu AM, et al. Factors and outcomes associated with the induction of labour in Latin America. BJOG. 2009;116:1762-72.

3. Carbone JF, Tuuli MG, Fogertey PJ, Roehl KA, Macones GA. Combination of Foley bulb and vaginal misoprostol compared with vaginal misoprostol alone for cervical ripening and labor induction: a randomized controlled trial. Obstet Gynaecol. 2013;121(2 Pt 1):247-52.

4. Kashanian M, Akbarian AR, Fekrat M. Cervical ripening and induction of labor with intravaginal misoprostol and Foley catheter cervical traction. Int $\mathbf{J}$ Gynaecol Obstet. 2006;92:79-80.

5. Chung JH, Huang WH, Rumney PJ, Garite TJ, Nageotte MP. A prospective randomized controlled trial that compared misoprostol,Foley catheter and combination misoprostol-Foley catheter for labor induction. Am J Obstet Gynecol. 2003;189:1031-5.

Cite this article as: Bhatiyani BR, Gandhewar MR, Kapsikar S, Gaikwad P. A study comparing vaginal misoprostol alone with vaginal misoprostol in combination with Foley catheter for cervical ripening and labour induction. Int J Reprod Contracept Obstet Gynecol 2017;6:485-8. 